\title{
Temporal control during maintenance and extinction of conditioned keypecking in ring doves
}

\author{
TATSUYA OHYAMA \\ Columbia University, New York, New York \\ JOHN GIBBON \\ New York State Psychiatric Institute, New York, New York \\ and Columbia University, New York, New York \\ and \\ JAMES D. DEICH and PETER D. BALSAM \\ Bamard College of Columbia University, New York, New York
}

\begin{abstract}
Timing of conditioned keypecking was investigated using a delay autoshaping procedure. In two experiments, the CS-US interval (ISI) was varied and the temporal pattern of responding during unreinforced probe trials extending beyond the reinforced ISI was recorded. Both experiments showed temporal control of keypecking at ISIs of 4, 8, and $16 \mathrm{sec}$, regardless of whether the probe duration was held constant (Experiment 1) or covaried with the ISI (Experiment 2). Analyses showed that the timing of keypecking was scalar. Increased responding near the end of the probe was due possibly to independent timing of the probe duration. In a third experiment, a group of subjects trained at an ISI of 8 sec were extinguished by presentation of only probe trials. Although the maximal response rate declined progressively, timing of keypecking did not change.
\end{abstract}

The ability of animals to time the occurrence of biologically significant events has been documented extensively in instrumental conditioning procedures. For example, in a fixed-interval (FI) schedule, reinforcement (e.g., food) occurs only if the animal responds after a certain time interval has elapsed since the last reinforcer. In the early stages of training, responding during the interfood interval exhibits the so-called "fixed-interval scallop," in which the rate of responding increases gradually as the time since the last reinforcer elapses (Ferster \& Skinner, 1957). Often, with increased training, this pattern gives way to a break-run pattern of responding on individual trials in which there is an abrupt transition from nonresponding to responding (Baron \& Lienenweber, 1994; Schneider, 1969; Shull \& Brownstein, 1970; but see Dews, 1978). In the break-run pattern, the point of transition varies across trials, and the FI scallop is observed as a result of averaging across trials (Schneider, 1969). Regardless of this difference, however, the pattern of be-

The present report is based in part on a thesis submitted by the first author to Columbia University in partial fulfillment of the requirements for the Master's degree. Portions of the data were presented at the annual meeting of the Eastern Psychological Association in Philadelphia, March 1996. We thank Kathy Kao, Elizabeth Pearson, and Heather WalkerWilson for their assistance in conducting the experiments. Correspondence concerning this article should be addressed to T. Ohyama, Department of Psychology, Columbia University, 406 Schermerhorn Hall, New York, NY 10027 (e-mail: tatsuya@paradox.psych.columbia.edu). havior is indicative of a temporal discrimination since there are no other apparent cues in the environment correlated with time, and since control animals reinforced on a variable-interval (VI) schedule with the same mean interfood interval do not respond differentially in time. In conditioning situations where time between events is the only source of stimulus control, the temporal distribution of responses during the interval exhibits lawful changes in accord with the reinforced time interval. Specifically, in accord with scalar expectancy theory (Gibbon, 1977, 1991), it has been commonly found that the mean and spreads of the temporal distribution of instrumental responses increase in proportion to the reinforced time interval, $\mathrm{T}$.

The relationship between the reinforced time interval and measures of the temporal response distribution has been studied extensively using the peak procedure, first utilized by Bitterman (1964) to study temporal control in Pavlovian procedures and later by Catania and others in operant procedures (Catania, 1970; Roberts, 1981). The procedure is a variant of the FI schedule in which a discriminative stimulus signals reinforcement after a fixed interval $\mathrm{T}$ on half of the trials but remains on past the scheduled time of reinforcement on the other half of the trials and is not reinforced (peak trials). As in the standard FI schedule, responding during FI trials may initially show scalloping (Zeiler \& Powell, 1994) but, with sufficient training, exhibit a break-run pattern (Church, Meck, \& Gibbon, 1994). During peak trials, animals with extensive training show temporal distributions of respond- 
ing in which the rate of responding averaged across trials peaks approximately at the scheduled time of reinforcement and decreases almost symmetrically around this time (commonly referred to as the peak time). Temporal gradients obtained by training subjects at different values of T show superposition, the hallmark of scalar timing (Gibbon, 1991). Superposition refers to the fact that when the gradients during peak trials are rescaled with respect to the reinforced $T$ and the maximal response rate, the gradients overlay upon one another. It shows that the relationship between the reinforced time and the spread of the temporal gradient is proportional. This, in turn, implies a constant coefficient of variation, $\gamma=\sigma / T$, where $\sigma$ is a measure of the spread of the temporal response distribution.

Superposition has been found not only in the peak procedure but in various other instrumental conditioning procedures as well (Gibbon, 1977, 1991). There is evidence indicating that this sort of timing also occurs in classical conditioning procedures (Brown \& Hemmes, 1997; Frey \& Ross, 1968; Pavlov, 1927; Rosas \& Alonso, 1996). However, few studies have used procedures analogous to the peak procedure in which test trials allow for the determination of the temporal generalization of conditioned responding past the normally reinforced $\mathrm{CS}$ duration (but see Bitterman, 1964, 1965; Longo, Klempay, $\&$ Bitterman, 1964). The purpose of the first two experiments was to see if a scalar timing model could account for the within-trial distributions of responding in an autoshaping procedure similar to the peak procedure. Unreinforced probe trials extending beyond the standard CS duration were interspersed among reinforced trials to assess the temporal control of keypecking. In both experiments, we looked for superposition of temporal response gradients when the CS-US interval or interstimulus interval (ISI) was varied. A third experiment investigated the effects of extinction on the temporal distribution of responses during probe trials.

\section{EXPERIMENT 1}

In Experiment 1, we investigated timing of conditioned keypecking in an autoshaping procedure. We used unreinforced probe trials of constant duration, in which the CS remained on past the standard CS duration, and varied the duration of the ISI across training conditions. If the scalar property holds, the spread of the temporal distribution of CRs during unreinforced probe trials should increase in proportion to the ISI.

\footnotetext{
Method

Subjects. Six ring doves (Streptopelia risoria) bred and housed in the Barnard laboratory and maintained at $85 \%$ of their free-feeding weight, served as the subjects. Two subjects were experimentally naive and 4 subjects had a prior history of exposure to autoshaping.

Apparatus. Two identical experimental chambers (Lehigh Valley/ BRS models) were used. The internal dimensions were $30 \times 30 \times$ $26 \mathrm{~cm}$, and the walls were painted flat black. The floor consisted of six hinged panels. In each chamber, the response key was positioned $7 \mathrm{~cm}$ to the left of the midline of the front panel and $13 \mathrm{~cm}$
}

above the floor. An IEE stimulus projector located behind the response key served to illuminate the key during trials. The minimum force required to activate this response key was $18 \mathrm{~N}$. A feeder aperture $(6.5 \times 7.0 \mathrm{~cm})$ was located in the center of the front panel and $2 \mathrm{~cm}$ above the floor. During grain presentation, the hopper was illuminated by one 24 PSB bulb. Head insertions into the hopper were monitored by a photocell. At all other times during the session, four No. 1829 lights aligned across the top of the front panel served as houselights. A PC situated in an adjacent room was used to control stimulus presentations and record data.

Procedure. Each naive subject was given hopper training for two daily sessions consisting of 30 feeder presentations on a VI 40 -sec schedule. Each session began with the houselights turned off, with the feeder elevated into feeding position, and the hopperlight turned on. Twenty seconds after the subject's head interrupied the photobeam, the feeder was retracted and the houselights were turned on. On each of the next 30 feeder presentations, the houselights were turned off and the hopper light was turned on. Access to grain was terminated $3 \mathrm{sec}$ after the subject's head interrupted the photobeam. The maximum amount of time allowed for the subject to get to the hopper and begin eating was $10 \mathrm{sec}$.

After hopper training, subjects were run 5 days per week on each training phase with transitions between conditions always preceded by a session of the current condition on the day prior to the transition. All training phases lasted either 20 or 21 days. There were no systematic differences as a function of the amount of training, and the data are not treated separately. Each session consisted of 20 presentations of the keylight CS followed by the US ( 4 sec of access to grain), 12 presentations of the CS alone, and 8 unreinforced presentations of a CS of long duration (probe trials). Trials were programmed such that in each block of 10 trials, 5 paired trials, 3 CS-alone trials, and 2 probe trials occurred. Within each block, the trials were presented randomly. A minimum interval of $16 \mathrm{sec}$ always followed the termination of each CS presentation, and the mean ITI was $32 \mathrm{sec}$. Each training phase consisted of exposure to a single ISI. In all conditions, the probe duration was set at $32 \mathrm{sec}$. The duration of the ISI was 4,8 , or $16 \mathrm{sec}$. Four subjects were exposed to the 8-, 4-, and 16-sec conditions, in that order. The remaining subjects were exposed to the $4-\mathrm{sec}$, then 8 -sec, and finally 16 -sec conditions.

\section{Results}

Mean response rates during probe trials averaged across the last 4 days of each phase are shown in Figure 1. No pecks were observed for 1 subject on one of these days. For that subject one prior day was used to compute the 4-day average. The data are plotted in $1-\mathrm{sec}$ bins. Response rates in each bin were calculated by dividing the mean number of cumulative responses per bin during a session by the mean number of probes with at least one peck (i.e., a running rate). The response patterns differed in the three conditions. In the 4- and 8-sec conditions, responding peaked very early in the trial and then declined, recovering somewhat near the end of the trial. In the 16-sec condition, responding increased abruptly to a moderate level, slowly increased to a maximum, and declined gradually after the standard ISI had elapsed. We excluded the first data point from all analyses of absolute and rescaled data, because the initial response rates reflect processes other than timing. (There is a minimum latency for the subject to get to the keylight after its onset to initiate pecking; this is reflected in the low response rates in the first bin for all conditions.) A two-way repeated measures analysis of variance (ANOVA) on the absolute response rates with 


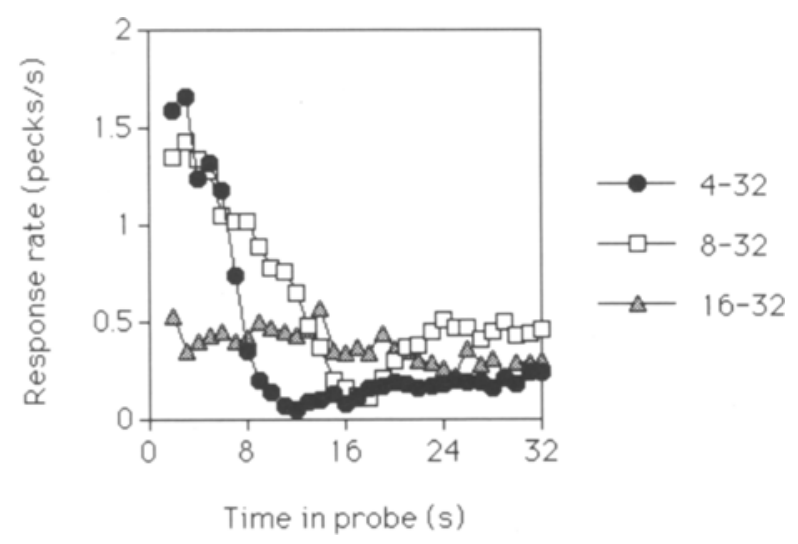

Figure 1. Mean response rates as a function of the absolute time elapsed in the probe trial in Experiment 1. The data are averaged over the last 4 days of training.

ISI and time in probe as within-subjects factors revealed significant effects of time in probe $[F(30,150)=10.46$, $p<.01]$ and an ISI $\times$ time interaction $[F(60,300)=6.13$, $p<.01]$. There was no main effect of ISI $[F(2,10)=$ $1.31]$.

Figure 2 shows the response rates for each condition rescaled by the maximum rate of the corresponding average response distribution, plotted as a function time elapsed in the probe trial. Here, time elapsed is expressed in terms of the time relative to the standard ISI. The data for each condition (ISIs of 4, 8, and $16 \mathrm{sec}$ ) are pooled into $1-, 2-$, and 4-sec bins, respectively, and plotted up to twice the standard ISI. A two-way repeated measures ANOVA on data rescaled for each individual subject yielded a significant main effect of relative time $[F(6,30)=12.68, p<$ $.01]$. Overall, there was no effect of ISI $[F(2,10)=2.40]$ nor an ISI $\times$ time interaction $[F(12,60)<1]$.

We used the method applied to the peak procedure by Meck (in press) to obtain values analogous to peak times. However, we refrain from using the term "peak time" to describe our data, since the gradients obtained were highly skewed and the values did not always agree well with the actual peaks in the gradients. Instead, we will refer to the values as "middle times" and reserve the term "peak times" for use in our discussions within the broader theoretical framework. From average response rates for each individual, middle times were calculated by taking the middle times of the first and last time bins exceeding $60 \%$ of the maximal response rate during the probe trial. Mean middle times were $3.9,5.8$, and 10.7 , respectively, for the 4-, 8-, and 16-sec CS conditions. A repeated measures ANOVA with ISI as the within-subjects factor yielded a significant effect of ISI $[F(2,10)=6.21, p<.05]$. However, there was no significant effect of ISI on middle times rescaled with respect to the standard ISI.

\section{Discussion}

Temporal control of keypecking during CS presentation was evident in all conditions. Response rates increased rapidly to a high level following CS onset and decreased after the duration of the standard ISI had passed. In absolute time, the temporal distributions of response rates varied as a function of the ISI, as indicated by the significant ISI $\times$ time interaction (Figure 1). In contrast, when the data were plotted in time relative to the ISI and maximal response rate, the gradients showed superposition, as indicated by the lack of an ISI $\times$ time interaction (Figure 2). Thus, the timing of keypecking was affected by the ISI and was scalar up to at least twice the ISI. Analyses of middle times showed that the effect of ISI on absolute middle times disappeared when the data were rescaled, again suggesting that timing was scalar. Although there was no significant effect of ISI in the rescaled data, the gradient in the 16-sec condition appeared flatter than those in the other conditions. However, the elevated responding near the end of the probe in the 16-sec condition may reflect processes other than excitation around the training ISI. Note that there was also an increase in response rate near the end of the probe trial in both the 4- and 8-sec conditions (Figure 1). It is possible that whatever process was responsible for this increased responding, it may have contributed to responding during the latter half of the probe in the 16-sec condition. Experiment 2 was designed to obtain temporal distributions of responding when probe trials were long enough so that responding near the end of probes would not contribute to responding around the training ISI.

\section{EXPERIMENT 2}

The results of Experiment 1 indicated that the timing of conditioned keypecking during probe trials approximately conformed to the scalar property. In addition to the temporal gradient generated by the presentation of reinforcement at the standard ISI, a separate process appeared to contribute to the overall temporal response gradient near the end of the probe trial. A previous study using the peak procedure showed a similar asymmetry in the resulting temporal generalization gradients (Church, Miller, Meck, \& Gibbon, 1991). These authors hypothesized that the secondary increase near the end of peak tri-

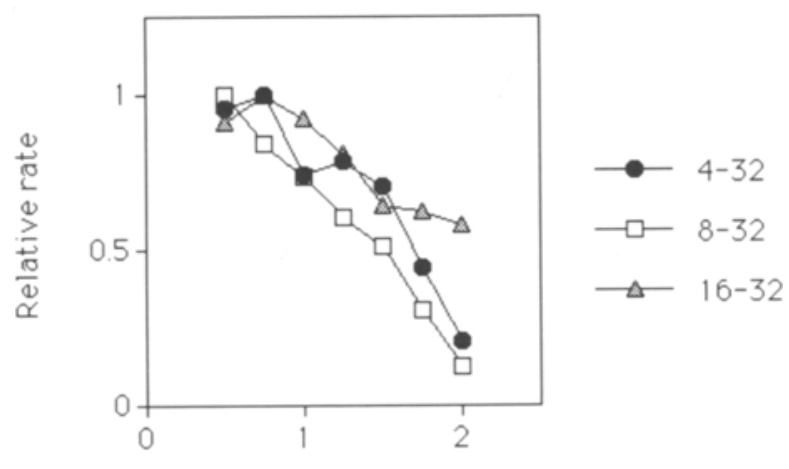

Time relative to $|S|$

Figure 2. Rescaled response rates plotted as a function of the relative time elapsed in the probe trial in Experiment 1 . The data were pooled into 1-, 2-, and 4-sec bins, respectively, for the 4-, 8-, and 16-sec conditions. 


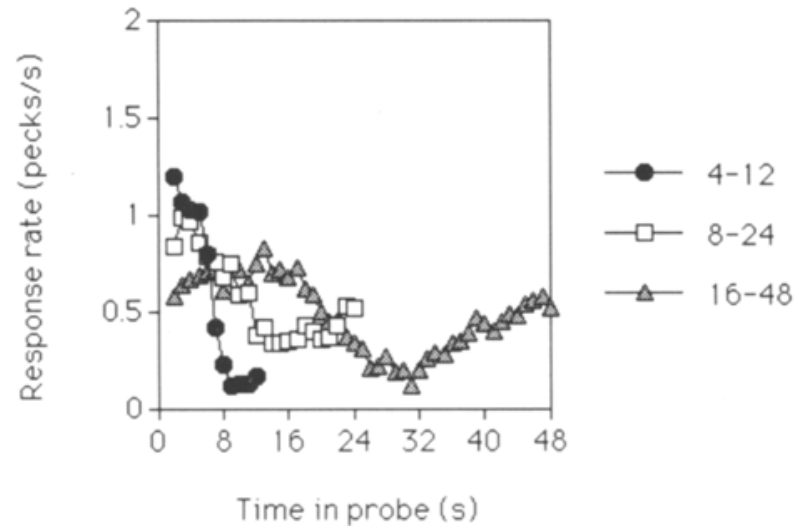

Figure 3. Mean response rates as a function of the absolute time elapsed in the probe trial in Experiment 2.

als reflected anticipation of the end of the trial. In an investigation of simultaneous timing of multiple intervals in pigeons, Leak and Gibbon (1995) found that when subjects were given mixed-interval FI training with three intervals of 15,50 , and $120 \mathrm{sec}$, they showed peaks at $15 \mathrm{sec}$ but not at 50 or $120 \mathrm{sec}$. They noted that the ratio between 50 and 15 (3.33:1) was sufficient for a peak to be discerned at $15 \mathrm{sec}$, but that the ratio between 120 and 50 (2.4:1) was not large enough for a discernible peak to occur at $50 \mathrm{sec}$. Such evidence suggests that if the animals in the previous experiment were anticipating two intervals (the end of the probe trial as well as the standard time of reinforcement presentation) then responding produced by the two anticipations may have interacted differently in the three conditions. Therefore, in Experiment 2 , we extended the length of the probe trials in the 16-sec condition to $48 \mathrm{sec}$ and adjusted the probe durations for the 4- and 8-sec conditions such that the probeto-ISI ratio was constant at $3: 1$. With these procedural changes, we sought again to see whether keypecking during the probe trial would exhibit the scalar property.

\section{Method}

Subjects. The 6 ring doves of Experiment 1 again served as the subjects.

Procedure. The apparatus used was identical to that of Experiment 1. Subjects were exposed to three conditions in which the duration of the probe was three times that of the ISI. The ISIs in each phase were 4, 8, and $16 \mathrm{sec}$, as in Experiment 1 . The respective probe durations in each phase were 12,24 , and $48 \mathrm{sec}$. Four subjects received training in the order of 8,16 , and $4 \mathrm{sec}$. Two other subjects were trained in the order of 16,4 , and $8 \mathrm{sec}$. There were no apparent effects of order, and the data were pooled across subjects. All subjects were trained on each condition for 20 or 21 days. With the exception of the 8-sec condition, which was run daily for the first 4 subjects, all training sessions were run 5 days per week. Data were analyzed as in Experiment 1.

\section{Results}

Figure 3 shows the average response rates during the probe trials on the last 4 days of training, plotted as a function of absolute time in $1-\mathrm{sec}$ bins. In all conditions, response rates were near maximal early in the trial, then decreased to a minimum around twice the training ISI, increasing again near the end of the probe trial. A twoway repeated measures ANOVA conducted on the absolute data from each condition up to $12 \mathrm{sec}$ yielded significant effects of time in probe $[F(10,50)=4.96, p<.01]$ and an ISI $\times$ time interaction $[F(20,100)=4.24, p<.01]$. There was no main effect of ISI $[F(2,10)<1]$. In addition, a separate two-way ANOVA was conducted on the data from only the 8-and 16-sec conditions up to $24 \mathrm{sec}$, and again there was a significant effect of time in probe $[F(22,110)=2.44, p<.01]$, as well as a significant ISI $\times$ time interaction $[F(22,110)=2.11, p<.01]$.

Figure 4 shows response rates for each condition rescaled by the maximum rate of the corresponding average response distribution, plotted as a function of relative time elapsed in the probe. As in Experiment 1, the data are pooled into 1-, 2-, and 4-sec bins, respectively, for the 4-, 8-, and 16-sec conditions and plotted up to twice the ISI. A two-way repeated measures ANOVA with relative time and ISI as the within-subjects factors was conducted on data rescaled for each individual subject. This revealed a significant effect of relative time $[F(6,30)=10.44, p<$ $.01]$ but neither an effect of ISI $[F(2,10)<1]$ nor an ISI $\times$ time interaction $[F(12,60)<1]$, indicating that the gradients up to twice the standard ISI superimposed.

Middle times were calculated from the average response rates, as in Experiment 1, using data up to twice the ISI. The mean middle times were $4.0,6.0$, and $12.2 \mathrm{sec}$ for the 4-, 8-, and 16-sec CS conditions, respectively. These data were subjected to a one-way repeated measures ANOVA. This yielded a significant main effect of ISI $[F(2,10)=11.96, p<.01]$. When the middle times were rescaled with respect to the ISI, a one-way repeated measures ANOVA revealed no effect of ISI $[F(2,10)=2.00]$.

\section{Discussion}

Clear temporal control of keypecking during the probe trial was seen in all conditions, including the $16-\mathrm{sec}$ condition. Response rates increased rapidly following CS onset and then decreased to a minimum around twice the ISI. In addition, responding increased near the end of the probe trial. Temporal gradients varied as a function of ISI, as indicated by the significant ISI $\times$ time interactions obtained from the separate two-way ANOVAs (Figure 3). Again when the data were plotted in time relative to the ISI, the gradients showed good superposition up to twice the ISI, as indicated by the lack of a significant ISI $\times$ time interaction (Figure 4). Superposition indicates that timing of conditioned keypecking during the probe trial was controlled by a scalar process up to twice the ISI. Additionally, analyses of middle times also supported this conclusion, as the significant effect of ISI on absolute middle times disappeared when the data were rescaled with respect to the standard ISI.

\section{EXPERIMENT 3}

The purpose of the next experiment was to examine how the temporal distribution of responding changes in 


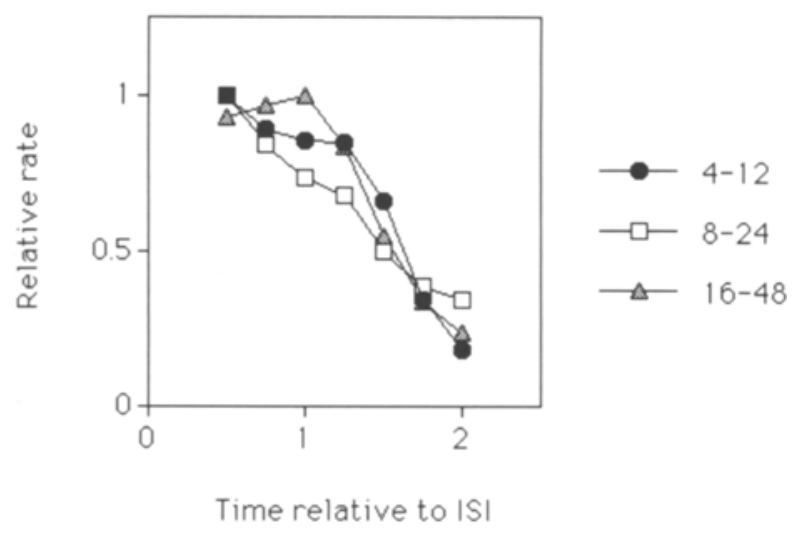

Figure 4. Rescaled response rates as a function of the relative time elapsed in the probe trial in Experiment 2. The data were pooled into 1-, 2-, and 4-sec bins, respectively, for the 4-, 8-, and 16-sec conditions.

extinction. There are several sorts of changes that could be predicted on the basis of theories of timing and extinction. Two analyses suggest that extinction might produce a rightward shift in peak times. First, according to the behavioral theory of timing (BeT; Killeen \& Fetterman, 1988), the rate of the underlying clock is proportional to the reinforcement rate. Thus, one could predict that, in extinction, clock speed should slow and peak times shift to the right. Second, from another theoretical point of view, extinction occurs because nonreinforced exposure to the CS causes the expected time of reinforcement in a CS to increase (Gallistel, 1990, 1992; Gallistel \& Gibbon, 1998). To the extent that temporal patterning reflects the anticipation of a specific time to reinforcement, again we might find rightward shifts in peak times in extinction.

We would also expect a change in the variance of the distribution on the basis of previous theoretical and empirical work on extinction. Behavioral variability in many aspects of behavior, such as rate, location, and force, have been reported to increase in extinction (see Stokes \& Balsam, 1991, for a review). One timing theory, BeT, specifically predicts an increase in timing variability during extinction. For these reasons, the timing of behavior might also become more variable during extinction.

\footnotetext{
Method

Subjects. Eight ring doves, bred and housed in our own laboratory, served as the subjects. As in Experiments 1 and 2, they were kept at $85 \%$ of their free-feeding weight. These subjects had a prior history of autoshaping in which they were exposed to pairings of a 8 -sec keylight CS and grain for approximately 20 sessions.

Procedure. The experimental apparatus was identical to those of Experiments 1 and 2. The procedure was similar to the previous two experiments, except for the modifications described below. First, the mean ITI was lengthened during acquisition. Second, only probe trials ( 40 per session) were presented in extinction, in order to increase the sampling rate for detecting any changes in the temporal distribution of responding in the CS. All other aspects of the training situation were identical to those of initial acquisition.
}

During acquisition, the CS duration was constant at $8 \mathrm{sec}$ and the probe duration was constant at $48 \mathrm{sec}$ for all subjects. The mean ITI was $96 \mathrm{sec}$. Training continued for 22 days until responding appeared stable. Extinction then began midweek and continued for 7 consecutive days. Subjects that did not respond at least once on $75 \%$ of the probe trials on more than 2 of the last 5 days prior to extinction were excluded from the analysis. One subject failed to meet this criterion.

Maximum response rates during successive blocks of 40 probe trials were obtained for each subject. The data during maintenance training were thus from the last five sessions, while the extinction data were from each session of extinction. Middle times in each block of trials for each subject were calculated, as in Experiments 1 and 2 , by taking the midpoint of the first and last time bin to cross $60 \%$ of the maximal response rate, based on pooled data up to three times the ISI. This criterion was chosen so that any shifts of the middle time to the right could be detected readily. Variability of the temporal response distribution was calculated by taking the standard deviation of the frequency distribution of the response times across 40 probe trials up to $3 \mathrm{~T}$. Sensitivity to time was calculated by dividing the standard deviation of frequency distribution by the middle time.

\section{Results}

Figure 5 shows the average rate of responding as a function of the time into the probe on the last 5 days of training (Days 18 to 22 , with a total of 40 probe trials). Also shown are the distributions of responding in successive blocks of 40 probe trials during extinction. During stable-state responding, response rates increased to a maximum near the scheduled time of reinforcement, then decreased to a minimum at approximately twice the ISI. Responding persisted at low levels throughout the rest of the probe trial. Responding during extinction showed the same pattern of responding, but at a reduced rate. Response rate increased to a maximum near the scheduled time of reinforcement and decreased to a minimum at approximately twice the ISI. The level of responding remained low throughout the remainder of the probe trial. A two-way repeated measures ANOVA was conducted on absolute response rates with time in probe and blocks as within-subjects factors. This revealed significant main effects of blocks $[F(3,18)=10.65, p<.01]$ and time in probe $[F(46,276)=10.29, p<.01]$ as well as a blocks $\times$ time interaction $[F(138,828)=6.84, p<.01]$.

Figure 6 shows the response rates for each condition rescaled by the maximum rate of the corresponding average response distribution, plotted as a function time elapsed in the probe trial. The data are plotted up to 2.5 times the ISI in $1-\mathrm{sec}$ bins. The relative distribution of responses in time was similar across trial blocks. To analyze the data, response rates in each block were rescaled by the average maximal rate for each subject up to twice the ISI (i.e., $16 \mathrm{sec}$ ). For 1 subject that failed to respond in the final block, the means of the rescaled rates for the remaining 6 subjects were substituted in each time bin. A twoway repeated measures ANOVA with blocks and time in probe as the within-subjects factors revealed a significant main effect of block $[F(3,18)=9.11, p<.01]$ and time in probe $[F(14,84)=9.47, p<.01]$ but no effect of a time $\times$ block interaction $[F(42,252)=1.03]$, indicating 


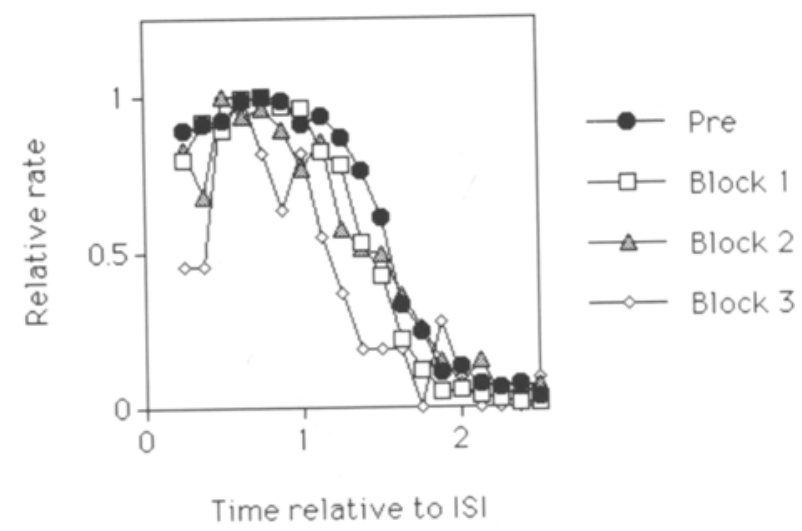

Figure 5. Mean overall response rates as a function of the absolute time elapsed in the probe trial in Experiment 3. Pre refers to the performance during the last five sessions of maintenance training. Blocks 1-3 refer to performance during successive blocks of $\mathbf{4 0}$ probe trials presented in extinction.

that the shape of the gradients did not change as a function of time in extinction.

Figure 7 shows the means of the three measures (maximum response rate, middle time, and sensitivity) plotted on a logarithmic scale as a function of blocks. Mean maximum response rates slowly declined in extinction. The mean middle times, however, were relatively constant, as were the mean sensitivities. One-way ANOVAs (repeated measures) with blocks as the within-subjects factor were conducted on these three measures. This revealed a significant main effect of blocks on maximum rate $[F(3,18)=$ $14.15, p<.01]$. There was no effect of blocks on either middle time $[F(3,18)=1.40]$ or sensitivity $[F(3,18)=$ 1.76].

\section{Discussion}

As in the previous experiments, there was good temporal control of responding during CS-US pairings. In fact, the temporal control observed in the current experiment appeared to be somewhat sharper than that obtained in Experiments 1 and 2. Subjects tended to respond less during the early part of a trial than they did in the previous two experiments. Furthermore, subjects also responded less near the end of probe trials. Whether this is because of continued training or parameter differences, we cannot say.

When reinforcement was discontinued, the level of responding controlled by the CS declined. However, neither the time of peak responding nor the sensitivity of timing changed. This decline of peak responding in extinction is similar to the decline in response amplitude that is observed during extinction of the conditioned nictitating membrane response (NMR) (Coleman \& Gormezano, 1971). In that preparation peak amplitude declines but the timing of the peak remains unchanged in extinction. The fact that peak times do not change in extinction has several theoretical implications.
First, in BeT (Killeen \& Fetterman, 1988), clock speed is assumed to be directly related to the reinforcement rate. Thus one might expect the clock to slow down in extinction causing a rightward shift in peak times. In addition, slowing of the pacemaker would be expected to increase the variance of the timing distribution (Fetterman \& Killeen, 1991; Killeen \& Fetterman, 1988). Neither of these predictions was confirmed. Thus, the current result seems inconsistent with that view unless there are other factors affecting clockspeed in extinction. For example, the underlying reason for the predicted shift in peak times is that clock speed depends on arousal. Perhaps the frustration (Amsel, 1992) of nonreward produces sufficient arousal to maintain clock speed during extinction.

These results also bear on some views of extinction. One possible account of extinction is that the cumulated CS time in extinction causes subjects to increase the expected time to reinforcement. Increases in expected time to reinforcement would be expected to decrease response rate and to move peak responding later and later into a test trial. The current result is at least incompatible with the latter prediction of such an account. However, cumulative time in extinction may still be the basis for the decision about whether or not to respond at all (Gallistel, 1990, 1992; Gallistel \& Gibbon, 1998).

\section{GENERAL DISCUSSION}

\section{CR Timing}

The present experiments provide evidence for scalar timing of conditioned keypecking in a modified autoshaping procedure. Experiment 1 showed that when probe trials were of constant duration, the temporal distribution of keypecking during these probes varied as a function of the training ISI. Experiment 2 yielded similar results when the probe duration was consistently three times the ISI. In both experiments, the response gradients superposed up to twice the ISI when plotted in relative time and

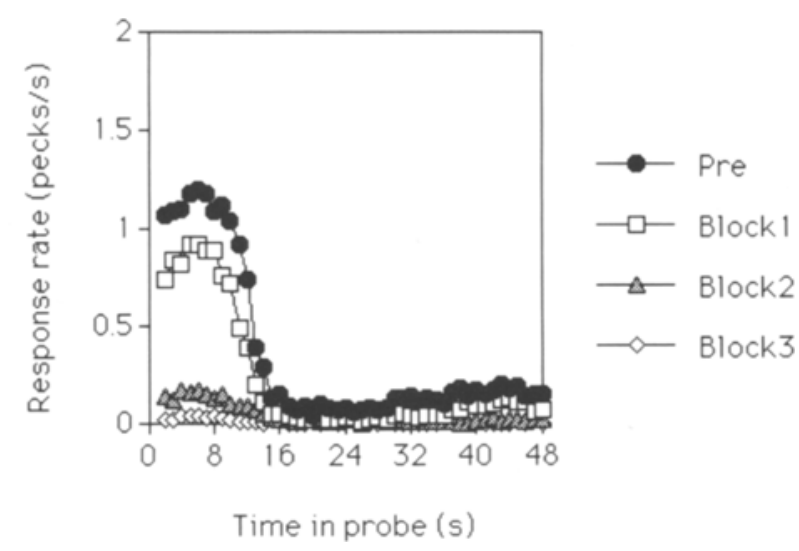

Figure 6. Rescaled response rates as a function of the relative time elapsed in the probe trial in Experiment 3 . The data are plotted in 1-sec bins. 


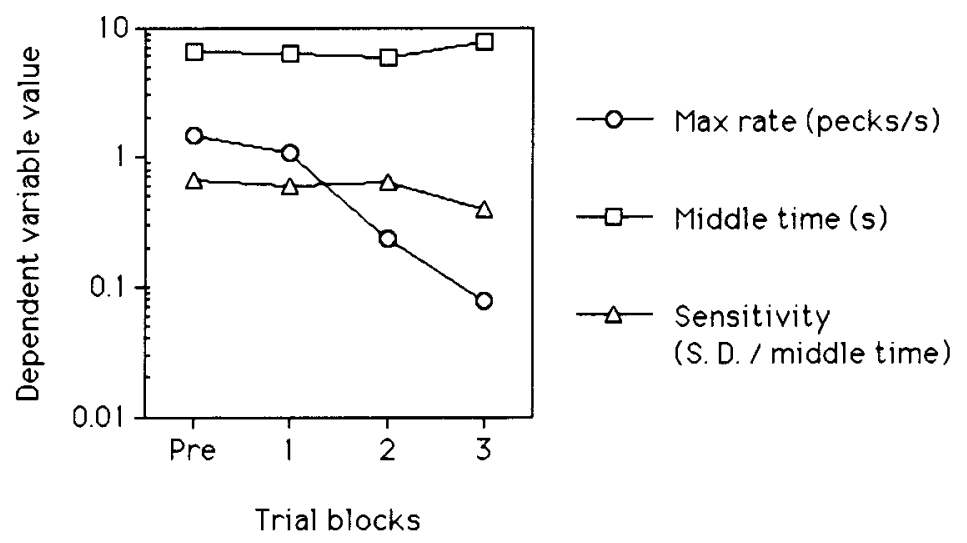

Figure 7. Mean values of the maximum response rate, middle time, and sensitivity index, plotted as a function of successive $\mathbf{4 0}$ trial blocks in Experiment 3. The ordinate is scaled logarithmically.

proportional response rate, showing that timing of conditioned keypecking was scalar. The results are similar to those found in the peak procedure, in that the temporal distributions of responding are scalar with respect to the scheduled time of reinforcement presentation. The sensitivity to time is also similar in that by approximately twice the duration of the ISI responding declines to minimal levels (see Roberts, 1981, for data from the peak procedure). The results are also similar to the effects of ISI on CR timing in rabbit NMR conditioning, in which the latency and peak amplitude of the conditioned response during unreinforced probe trials presented throughout training show changes proportional to the ISI (Gormezano, 1972; Smith, 1968). Scalar timing poses a new constraint for existing models of CR timing. Although numerous models combining biophysical, anatomical, neuralnetwork, and stimulus trace concepts are capable of simulating the temporal specificity of CR timing in rabbit NMR conditioning (Bartha, Thompson, \& Gluck, 1991; Desmond \& Moore, 1988; Fiala, Grossberg, \& Bullock, 1996; Grossberg \& Merrill, 1992; Moore, Desmond, \& Berthier, 1989), and some have been used successfully to test and confirm novel predictions (Desmond \& Moore, 1991), none offer any specific mechanism for generating scalar timing (but see Grossberg \& Merrill, 1992, for simulations of results from the peak procedure).

Two aspects of the temporal distributions of responding obtained in Experiments 1 and 2 differ from those usually obtained in instrumental procedures. First, response rates tended to peak earlier than the scheduled time of reinforcement, in contrast to the usual result where the peak time approximates the scheduled reinforcement time. The results are consistent with previous studies on pigeon autoshaping which report that the response rate reaches a maximum shortly following CS onset and declines during the remainder of the CS up to the point of US presentation (Deich \& Wasserman, 1977; Myerson, Myerson, \& Parker, 1979; Newlin \& LoLordo, 1976). A number of explanations may account for these results. One possibility is that a competing response (i.e., movement toward the hopper) caused a decrease in pecking during the latter portion of the ISI (Boakes, 1977). Indeed, there is evidence to suggest that such goal-tracking behavior may influence the temporal distribution of keypecking (Gibbon, Farrell, Locurto, Duncan, \& Terrace, 1980; Myerson et al., 1979; O'Connell \& Rashotte, 1982). However, the conditions in the present experiment did not favor its development. The present experiments involved partial reinforcement, minimal spatial separation between the keylight and hopper, and variation in trial and intertrial intervals, all conditions known to reduce the occurrence of goal tracking (Boakes, 1977; Gibbon et al., 1980; O'Connell \& Rashotte, 1982; Silva, Silva, \& Pear, 1992; van Hest, van Haaren, Kop, \& van der Schoot, 1986). Furthermore, casual observation of behavior during probe trials of videotaped sessions suggests that goal-tracking did not occur in these experiments. Rather, keypecking appeared to be inhibited for a period following the standard time of reinforcement presentation, after which responding resumed near the end of the probe. (Subjects typically turned away from the CS after a bout of pecking and stayed near the back wall of the chamber opposite to the wall with the keylight.) A third alternative consistent with this observation is that the early responding resulted from the interaction of an excitatory temporal gradient due to reinforcement of standard CS trials and an inhibitory temporal gradient resulting from nonreinforcement of probe trials. Probe trials were indistinguishable from a standard CS up to the usual time of reinforcement, but once the CS persisted for some time past the standard ISI, time-correlated stimuli could have served as cues for nonreinforcement to inhibit subsequent responding during the probe trial. The leftward shift in the peak of the response gradients may have occurred due to a "peak shift" (Spence, 1937) along the continuum of time. There is evidence for the plausibility of such an explanation. First, it seems that, in the peak procedure, subjects must learn to stop responding after the 
reinforced time has passed. Recent findings show that subjects tend to respond throughout peak trials when they are introduced for the first time after being trained only with discrete FI trials (Kirkpatrick-Steger, Miller, Betti, \& Wasserman, 1996). That is, the decline in responding after the reinforced ISI may require experience with nonreinforced times. The establishment of a time past reinforcement as a CS - could then affect the location of the peak. Siegel (1967) conditioned rats using a tone of fixed duration as the CS and shock as the US, and tested for generalization along the temporal dimension by measuring the startle response to a loud noise presented in place of the shock on test trials differing in CS duration. He found that a group of rats trained on a simple classical conditioning procedure with CS + showed symmetrical generalization gradients with a maximum at the trained value. In contrast, groups trained on a differential conditioning procedure where the standard tone was paired with shock but either a briefer or longer tone was never followed by shock showed gradients with peaks that were shifted toward the side of CS+ away from the CS-. Thus the early responding in our studies may have resulted from such an interaction between $\mathrm{CS}+$ and $\mathrm{CS}-$.

A second interesting aspect of the experimental data is the increased rate of responding near the end of the probe trial. Although such increases have also been found in the peak procedure, they have not been as pronounced. The interacting gradient account discussed above provides one explanation of the increase in responding near the end of the probe trial. Recovery of responding may occur if the shapes of the inhibitory and excitatory temporal gradients are such that, with elapsing time into the probe trial, excitation overcomes inhibition to produce a recovery in performance. This sort of account, however, is difficult to disconfirm unless independent measures of the shape of excitatory and inhibitory gradients are collected (Hearst, 1969). An alternative interpretation is that responding occurs in anticipation of the end of a trial (Brownstein \& Balsam, 1975; Church et al., 1991; Schwartz, 1972). The pattern of responding is highly similar to that reported for the simultaneous timing of multiple intervals (Leak \& Gibbon, 1995) and suggests that both the CS and probe may have been timed. Since the sum of the two anticipatory gradients depends heavily on the absolute difference between the duration of the standard ISI and the probe, this dual-anticipation hypothesis explains why, at equivalent standard ISIs, the temporal generalization gradients change with probe duration (compare Conditions 16-32 and 16-48).

The general results of Experiments 1 and 2 are in accord with data collected on temporal control of responding in instrumental procedures. The distribution of anticipatory CRs changed as a function of the ISI in accord with the scalar property. This result, taken together with other work showing that approach to the keylight is scalar
(Brown \& Hemmes, 1997), indicates that the entire sequence of approaching and pecking a keylight shows this property.

\section{Time and Conditioning}

The central finding of Experiment 3 was that extinction decreased the maximum response rate in a probe trial but did not change the timing of the response. The results are consistent with those from the peak procedure, rabbit NMR conditioning, and avoidance conditioning. In the peak procedure, presenting only peak trials results in a gradual decline in the height of the response distribution but no change in the peak time (Roberts \& Holder, 1984, Experiment 5). Similarly, shifting the ISI in the NMR conditioning preparation results in a decline in the amplitude of responding centered around the old ISI and the emergence of a new response distribution centered around the new ISI (Coleman \& Gormezano, 1971). Lastly, extinction reduces the probability of avoidance but has little effect on avoidance latency (Gibbon, 1972). Together, these results suggest that the learning of when to respond may be quite independent of the factors that determine whether or not to respond at all.

Other evidence for this independence comes from both behavioral and physiological studies of timing and conditioning. Roberts (1981), using the peak procedure, found that peak heights varied directly with the probability of reinforcement but peak times remained unchanged by this manipulation. Meck (in press) found that lesions of the substantia nigra eliminated temporal control in a peak procedure while preserving overall response rate differences produced by different expected times to reinforcement. Lesions of the nucleus accumbens did not affect temporal control but response rate differences (peak height) based on overall reinforcement rates were eliminated. Gibbon and Balsam (1981) noted that the speed of acquisition of keypecking in pigeon autoshaping was affected by the temporal parameters of conditioning situation, namely the CS duration and the interreinforcer interval, even before temporal control developed within a CS trial. Taken together, all of these data suggest the mechanisms that determine when to respond have some independence from those that determine how much to respond.

This independence of temporal control and overall associative value is similar to the independence of an occasion setter's ability to control target responding from its own associative value (Swartzentruber, 1995). Perhaps temporal cues act to occasion when a target cue is reinforced. This could take place in one of two ways. Time can act as a facilitator signaling when reinforcement will be presented or time can act as an inhibitor of responding during times when reinforcement is predictably absent. In either case, the modulatory role of time will be independent of the overall associative value of the target. 


\section{REFERENCES}

AMSEL, A. (1992). Frustration theory: An analysis of dispositional learning and memory. Cambridge: Cambridge University Press.

Baron, A., \& Lienenweber, A. (1994). Molecular and molar analyses of fixed-interval performance. Journal of the Experimental Analysis of Behavior, 61, 11-18.

Bartha, G. T., Thompson, R. F., \& Gluck, M. A. (1991). Sensorimotor learning and the cerebellum. In M. Arbib \& J. Ewert (Eds.), Visual structure and integrated functions (pp. 381-396). New York: Springer-Verlag.

Bitterman, M. E. (1964). Classical conditioning in the goldfish as a function of the CS-US interval. Journal of Comparative \& Physiological Psychology, 58, 359-366.

BitTerman, M. E. (1965). The CS-US interval in classical and avoidance conditioning. In W. F. Prokasy (Ed.), Classical conditioning (pp. 1-19). New York: Appleton-Century-Crofts.

BoAKEs, R. A. (1977). Performance on learning to associate a stimulus with positive reinforcement. In H. Davis \& H. M. B. Hurwitz (Eds.), Operant-Pavlovian interactions (pp. 67-101). Hillsdale, NJ: Erlbaum.

Brown, B. L., \& Hemmes, N. S. (1997). Timing of the CS-US interval by pigeons in trace and delay autoshaping. Quarterly Journal of Experimental Psychology, 50B, 43-50.

Brownstein, A. J., \& BalsAM, P. D. (1975). A search for conditioned reinforcement effects in negative automaintenance of keypecking. Bulletin of the Psychonomic Society, 6, 165-168.

Catania, A. C. (1970). Reinforcement schedules and psychophysical judgements: A study of some temporal properties of behavior. In W. N. Shoenfeld (Ed.), The theory of reinforcement schedules (pp. 142). New York: Appleton-Century-Crofts.

Church, R. M., Meck, W. H., \& Gibbon, J. (1994). Application of scalar timing theory to individual trials. Journal of Experimental Psychology: Animal Behavior Processes, 20, 135-155.

Church, R. M., Miller, K. D., Meck, W. H., \& Gibbon, J. (1991). Symmetrical and asymmetrical sources of variance in temporal generalization. Animal Learning \& Behavior, 19, 207-214.

Coleman, S. R., \& Gormezano, I. (1971). Classical conditioning of the rabbit's nictitating membrane response under symmetrical CS-US interval shifts. Journal of Comparative \& Physiological Psychology, 77, 447-455.

Deich, J. D., \& WasSERman, E. A. (1977). Rate and temporal pattern of key pecking under autoshaping and omission schedules of reinforcement. Journal of the Experimental Analysis of Behavior, 27, 399.405 .

DESMOND, J. E., \& MOORE, J. W. (1988). Adaptive timing in neural networks: The conditioned response. Biological Cybernetics, 58, 405415 .

Desmond, J. E., \& Moore, J. W. (1991). Altering the synchrony of stimulus trace processes: Tests of a neural-network model. Biological Cybernetics, 65, 161-169.

DEws, P. B. (1978). Studies on responding under fixed-interval schedules of reinforcement: II. The scalloped pattern of the cumulative record. Journal of the Experimental Analysis of Behavior, 29, 67-75.

Ferster, C. B., \& SKINNER, B. F. (1957). Schedules of reinforcement. New York: Appleton-Century-Crofts.

Fetterman, J. G., \& Killeen, P. R. (1991). Adjusting the pacemaker. Learning \& Motivation, 22, 226-252.

Fiala, J. C., Grossberg, S., \& Bullock, D. (1996). Metabotropic glutamate receptor activation in cerebellar Purkinje cells as substrate for adaptive timing of the classically conditioned eye-blink response. Journal of Neuroscience, 16, 3760-3774.

FreY, P. W., \& Ross, L. E. (1968). Classical conditioning of the rabbit eyelid response as a function of the interstimulus interval. Journal of Comparative \& Physiological Psychology, 65, 246-250.

Gallistel, C. R. (1990). The organization of learning. Cambridge, MA: MIT Press, Bradford Books.

Gallistel, C. R. (1992). Classical conditioning as an adaptive specialization: A computational model. In D. L. Medin (Ed.), The psy- chology of learning and motivation (Vol. 28, pp. 35-67). New York: Academic Press.

Gallistel, C. R., \& GibBon, J. (1998). Time and rate in classical conditioning. Unpublished manuscript.

GIBBON, J. (1972). Timing and discrimination of shock density in avoidance. Psychological Review, 79, 68-92.

GiBBON, J. (1977). Scalar expectancy theory and Weber's law in animal timing. Psychological Review, 84, 279-325.

GiBBon, J. (1991). Origins of scalar timing. Learning \& Motivation, 22, 3-38.

GibBon, J., \& Balsam, P. D. (1981). Spreading association in time. In C. M. Locurto, H. S. Terrace, \& J. Gibbon (Eds.), Autoshaping and conditioning theory (pp. 219-251). San Diego: Academic Press.

Gibbon, J., Farrell, L., Locurto, C. M., Duncan, H. J., \& Terrace, H. S. (1980). Partial reinforcement in autoshaping with pigeons. Animal Learning \& Behavior, 8, 45-59.

GormEZANO, I. (1972). Investigations of defense and reward conditioning in the rabbit. In A. Black \& W. F. Prokasy (Eds.), Classical conditioning $I I$ (pp. 151-181). New York: Appleton-Century-Crofts.

GrossberG, S., \& MERRILL, J. W. L. (1992). A neural network model of adaptively timed reinforcement learning and hippocampal dynamics. Cognitive Brain Research, 1, 3-38.

HEARST, E. (1969). Excitation, inhibition and discrimination learning. In N. J. Mackintosh \& W. K. Honig (Eds.), Fundamental issues in associative learning (pp. 1-41). Halifax, NS: Dalhousie University Press.

KiLleEn, P. R., \& Fetterman, J. G. (1988). A behavioral theory of timing. Psychological Review, 95, 274-295.

KirkPatrick-STeger, K., Mll.ler, S. S., Betti, C. A., \& Wasserman, E. A. (1996). Cyclic responding by pigeons on the peak timing procedure. Journal of Experimental Psychology: Animal Behavior Processes, 22, 447-460.

LEAK, T. M., \& GibBON, J. (1995). Simultaneous timing of multiple intervals: Implications for the scalar property. Journal of Experimental Psychology: Animal Behavior Processes, 21, 3-19.

Longo, N., Klempay, S., \& Bitterman, M. E. (1964). Classical appetitive conditioning in the pigeon. Psychonomic Science, 1, 19-20.

MEck, W. H. (in press). Neuroanatomical localization of an internal clock: A functional link between mesolimbic-mesocortical and nigrostriatal dopaminergic systems. Behavioural Brain Research.

Moore, J. W., Desmond, J. E., \& Berthier, N. E. (1989). Adaptively timed conditioned responses and the cerebellum: A neural network approach. Biological Cybernetics, 62, 17-28.

Myerson, J., Myerson, W. A., \& Parker, B. K. (1979). Automaintenance without stimulus-change reinforcement: Temporal control of keypecks. Journal of the Experimental Analysis of Behavior, 31, 395403.

Newlin, R. J., \& LoLordo, V. M. (1976). A comparison of pecking generated by serial, delay, and trace autoshaping procedures. Journal of the Experimental Analysis of Behavior, 25, 227-241.

O'Connell, J. M., \& Rashotte, M. E. (1982). Reinforcement magnitude effects in first-order and second-order conditioning of directed action. Learning \& Motivation, 13, 1-25.

Pavlov, I. P. (1927). Conditioned reflexes (G.V. Anrep, Trans.). London: Oxford University Press.

RoBERTS, S. (1981). Isolation of an internal clock. Journal of Experimental Psychology: Animal Behavior Processes, 7, 242-268.

ROBERTS, S., \& HoldER, M. D. (1984). What starts an internal clock? Journal of Experimental Psychology: Animal Behavior Processes, 10, 273-296.

Rosas, J. M., \& Alonso, G. (1996). Temporal discrimination and forgetting of CS duration in conditioned suppression. Learning \& $\mathrm{Mo}$ tivation, 27, 43-57.

SCHNEIDER, B. A. (1969). A two-state analysis of fixed-interval responding in the pigeon. Journal of the Experimental Analysis of Behavior, 12, 677-687.

SchwarTz, B. (1972). The role of positive conditioned reinforcement in the maintenance of keypecking which prevents delivery of primary reinforcement. Psychonomic Science, 28, 277-278. 
SHULL, R. L., \& BRownstein, A. J. (1970). Interresponse time duration in fixed-interval schedules of reinforcement: Control by ordinal position and time since reinforcement. Journal of the Experimental Analysis of Behavior, 14, 49-53.

SIEGEL, A. (1967). Stimulus generalization of a classically conditioned response along a temporal dimension. Journal of Comparative \& Physiological Psychology, 64, 461-466.

Silva, F. J., Silva, K. M., \& Pear, J. J. (1992). Sign- versus goal-tracking Effects of conditioned-stimulus-to-unconditioned-stimulus distance. Journal of the Experimental Analysis of Behavior, 57, 17-31.

SмIтн, M. C. (1968). The CS-US interval and US intensity in classical conditioning of the rabbit's nictitating membrane response. Journal of Comparative \& Physiological Psychology, 66, 679-687.

SPENCE, K. W. (1937). The differential response in animals to stimuli varying within a single dimension. Psychological Review, 44, 430444.
Stokes, P. D., \& BALSAM, P. D. (1991). Effects of reinforcing preselected approximations on the topography of the rat's bar press response. Journal of the Experimental Analysis of Behavior, 55, 213231.

Swartzentruber, D. (1995). Modulatory mechanisms in Pavlovian conditioning. Animal Learning \& Behavior, 23, 123-143.

van Hest, A., van HaAREN, F., Kop, P., \& van DER Schoot, F. (1986). Stimulus- and feeder-directed behavior in a long-box: Effect of fixed versus variable time schedules of food presentation. Animal Learning \& Behavior, 14, 168-172.

ZeILeR, M. D., \& Powell, D. G. (1994). Temporal control in fixedinterval schedules. Journal of the Experimental Analysis of Behavior, 61, 1-9.

(Manuscript received May 4, 1998;

revision accepted for publication August 6,1998 .) 